\title{
Best Evidence for the FAA Industry Training Standards (FITS) Program for Pilot Training in Technically Advanced Aircraft ${ }^{1}$
}

\author{
Wayne A. Dornan, Paul A. Craig, Steve Gossett, Wendy Beckman \\ Department of Aerospace, Middle Tennessee State University
}

\footnotetext{
${ }^{1}$ The results of this study were presented in preliminary form at the National Aircraft Training Symposium in Daytona Beach, Florida, March, 2006, and the International Symposium on Aviation Psychology, Oklahoma City, Oklahoma, April, 2005.
}

\section{ABSTRACT}

To continue the investigation of the effectiveness of FITS syllabus training, which was previously evaluated in a 2004 study, the MTSU Aerospace Department FITS research team has conducted a second study. In the original study, a group of students were trained in a FITS-approved combined Private/Instrument curriculum in technically advanced aircraft (TAA). The effectiveness of that training was compared, through the identification of setbacks and bottlenecks in training, to archival records of students who had been trained in "round dial" aircraft using a traditional flight training curriculum. In the October 2005 issue of the Collegiate Aviation Review, we reported that the FITS trained students experienced statistically significant fewer setbacks and bottlenecks than the traditionally trained students. The question that remained was whether the FITS syllabus or use of TAA was the determining factor in the positive results experienced. In the phase of the study reported in this article, a new group of students completed their Instrument Rating training, this time flying TAA but using a traditional curriculum. The results of all three groups of students can now be compared, and the evidence suggests that it is the FITS syllabus that is responsible for the improvements in training, not the use of TAA. Further, the results of several surveys administered in this study indicate that not only is FITS training more efficient due to reduced bottlenecks and setbacks, but that it is also more effective at preparing students to make real-life decisions in the flight environment.

\section{INTRODUCTION}

Until very recently, issues with automated flight decks were only relevant to the commercial air carrier industry (Billings, 1997; Fanjoy \& Young, 2005; Funk, Lyall, \& Niemczyk, 1997; Parasuraman \& Riley, 1997; Sarter \& Woods, 1995). This is no longer the case, however, with the advent of automated cockpits that have recently proliferated in the General Aviation (GA) community (AOPA Air Safety Foundation, 2005; Casner, 2005; Young, Fanjoy, \& Suckow, 2006). An automated aircraft is generally comprised of an integrated cockpit system consisting of a primary flight display, a multifunction display which includes a Global Positioning System (GPS) with traffic and terrain graphics, along with a fully integrated autopilot (AOPA Air Safety Foundation, 2005). In the GA community this type of aircraft, which requires the pilot to interface with at least one computer, is collectively known as a Technically Advanced Aircraft (TAA). It includes aircraft used in both VFR and IFR operations, with equipment certified to either VFR or IFR standards (AOPA Air Safety Foundation, 2005).

Not surprisingly, one key issue with the advent of this technology in GA aircraft is how to train pilots/students to take advantage of the increased safety opportunities that are available with the new technology (Fiduccia et al, 2003). In 1998, the FAA announced a "SAFER SKIES" initiative to achieve significant reductions in the number of GA fatal accidents by 2009. SAFER SKIES consists of two teams with similar goals to increase aviation safety. One of the teams, the General Aviation Joint Steering Committee (GAJSC) focuses on the leading causes of general aviation accidents. In order to assess what new safety challenges arise with the advent of the TAA, the GAJSC established a TAA safety study team to investigate safety issues with TAA aircraft. Part of the impetus for this was an observed increase in fatal accidents in TAA's (AOPA Air Safety Foundation, 2005; Fiduccia et al, 2003). This type of increase in the GA accident rate had also been observed in the mid-1990's, as aircraft that featured more technically advanced features became available 
to pilots (Fiduccia et al, 2003). One of the major recommendations of the GAJSC was that the current training format in the GA industry was insufficient to exploit the additional safety features of TAA's, and that there was a critical need to develop a TAA training program in the GA community (Fiduccia et al, 2003). This approach was adopted by the FAA in a FAA Industry Training Standards (FITS) program (Federal Aviation Administration, 2004), which emphasized the importance of "real world" training exercises in the form of scenario training. This approach had proven successful in the air carrier industry, but is not the accepted standard the GA community. This training places a major emphasis on: aeronautical decision making skills, risk management, situational awareness, and single pilot resource management (SRM) using real-time flight scenarios (Ayers, 2006; Glista, 2003).

In 2004, the MTSU Aerospace Department received FAA Part 141 approval to train students for a combined Private Pilot Certificate and Instrument Rating using the FITS curriculum. This new curriculum was developed by the FITS consortium (University of North Dakota and Embry-Riddle Aeronautical University) and first empirically tested as part of a MTSU/NASA cooperative agreement study in 2004 and 2005. Over the last two years, the Aerospace Department FITS research team has published and presented the results of several studies regarding FITS training (Craig, Bertrand, Dornan, Gossett, \& Thorsby, 2005a, 2005b; Dornan, Gossett, Craig, \& Beckman, 2006). In the first study, we compared the flight training records of 19 students who had obtained both their Private Pilot Certificate and Instrument Rating using the traditional flight training syllabus commercially available through Jeppesen (2003) in a "round dial" aircraft, with students who received a combined Private Pilot Certificate and Instrument rating using the FITS syllabus in a TAA. In both groups, we discovered a pattern of "setbacks" throughout the flight training. A setback was defined as a lesson of training that a student had to repeat. A comparison of setbacks between the two groups revealed that students using the traditional syllabus in round dial aircraft had fewer setbacks in their initial flight training, but then had a steady increase in setbacks throughout the reminder of their training. In contrast, the FITS trained students in the TAA had a greater number of setbacks early in their training (presolo), but these setbacks diminished significantly as their training progressed (Craig et al., 2005a, 2005b). This data strongly suggests that FITS trained pilots have fewer setbacks over their entire VFR/IFR training than traditionally trained pilots (Craig et al., 2005a, 2005b). In this initial study, however, the FITS trained students utilized a TAA while the traditional syllabus students did all of their flight training in a "round dial" aircraft. It could therefore be argued that the overall decrease in setbacks enjoyed by the FITS trained students were partly or completely the result of the automation, e.g. the TAA and not the syllabus effected the change. In other words, it was possible that the FITS flight training syllabus had very little impact on decreasing the number of setbacks. Consequently, in this second study the researchers decided to empirically test for this possibility by comparing a group of students who had obtained their Instrument Rating in a TAA using the traditional Jeppesen syllabus with a group of FITS trained students in a TAA. If indeed it is the FITS training that makes the difference, then students who are traditionally trained in the TAA should experience the setbacks similar to those of the traditionally trained students in "round dial" aircraft. Conversely, if it is the utilization of the TAA that makes the difference, then the students trained using the traditional syllabus in the TAA should experience fewer setbacks as did the FITS trained students in the TAA. Therefore, in this study the primary goal was to empirically determine whether the FITS syllabus or the TAA was the driving force in the reduction of total setbacks. This was accomplished by comparing students who obtained the Instrument Rating in a TAA using the traditional syllabus, with students who obtained their Instrument Rating in a TAA using the FITS syllabus.

A secondary goal in this study was to compare the aeronautical decision making skills of FITS trained pilot versus traditionally trained pilots. For example, one major feature of the FITS training curriculum is that there is no minimum flight time needed to satisfy the 
requirements of either their Private Pilot Certificate, or an Instrument Rating (Federal Aviation Administration, 2004); the training is completely proficiency based. In contrast, traditional Part 141 or Part 61 students must meet several minimum flight time requirements to be eligible for a Private Pilot Certificate and then an Instrument Rating. In the initial study, the FITS trained students had significantly fewer total hours when they completed their combined Private Certificate and Instrument Rating than did the traditionally trained group (Craig et al., 2005a, 2005b). In fact, one of the FITS trained students received her Private/Instrument with a total of 54.5 airplane hours! This actually troubled the FITS research team as poor pilot decision making skills and a propensity to take risks has been reported to be related to the experience level of a pilot (Klein, 1998; Stokes, Kemper, \& March, 1992). In fact, flight experience has been reported to be positively correlated to effective decision making (Driskill, Weismuller, Quebe, \& Hand, 1998). This is particularly problematic as poor pilot decision making skills has been identified as a major contributing factor in several fatal aviation accidents (Craig, 2000; Jensen, 1982), and in particular in several recent accidents involving TAA's (AOPA Air Safety Foundation, 2005). As a result, one major concern with the FITS combined Private/Instrument Rating is that since pilots will have significantly fewer flight hours (e.g. experience) compared to more traditionally trained students, what type of decision making skills will they have? One unique aspect of the FITS training syllabus is that while it still teaches basic flying skills (e.g. stick and rudder), these skills are not learned via "drill and practice" but rather through realistic flight scenarios. Experience in a variety of scenarios where critical decisions and risk assessment are continually evaluated give FITS students practice in making these decisions, and during the de-briefing, feedback on these decisions. This type of approach which is inherent in the FITS training syllabus is believed to improve decision making skills in pilots. Consequently, in this study several questionnaires evaluating risk assessment were administered to both groups following their flight training in an attempt to determine whether FITS trained pilots were more or less conservative in their aeronautical decision making skills.

\section{METHODOLOGY}

This study was comprised of forty-six students majoring in Aerospace at Middle Tennessee State University (MTSU). The students were divided into three groups, 1) "Traditional Syllabus Glass" consisted of eleven students who received their instrument flight training in a TAA using a traditional flight training syllabus. The traditional flight training syllabus adopted by MTSU and approved by the FAA is the Instrument portion of the Jeppesen Instrument and Commercial syllabus (2003). This publication is commercially available and widely used as an industry standard throughout civilian flight training programs in the United States, 2) "FITS Glass": This group consisted of the sixteen students from our earlier study that were trained using the FITS training program in a TAA and 3), "Traditional Syllabus Round Archival" which consisted of the training records of 19 students who received their instrument flight training in a round dial aircraft using the traditional syllabus with completed flight training records. These training records served as archival data and were used to compare setbacks and bottlenecks over the course of the Instrument training with the other groups. In addition, participants in the Traditional Syllabus Glass and the FITS Glass groups were administered several questionnaires regarding personal IFR visibility and cloud minimums which were standardized in a previous study (Dornan, Craig, \& Gossett, 2006). Since the archival group consisted of past student training records, questionnaires could not be given to this group. Table 1 represents an overview of the study groups. 
Table 1. Study Groups

\begin{tabular}{|l|l|l|l|}
\hline GROUP NAME & AIRCRAFT & SYLLABUS & TIMEFRAME \\
\hline $\begin{array}{l}\text { Traditional } \\
\text { Syllabus Glass } \\
\mathrm{N}=11\end{array}$ & TAA & Jeppesen IFR & Fall 2005 \\
\hline \begin{tabular}{l|l|l|} 
FITS Glass \\
N=16
\end{tabular} & TAA & $\begin{array}{l}\text { FITS } \\
\text { Private/Inst }\end{array}$ & \\
\hline $\begin{array}{l}\text { Traditional } \\
\text { Syllabus Round } \\
\text { Archival } \\
\text { N=19 }\end{array}$ & Round Dials & Jeppesen IFR & $1999-2004$ \\
\hline
\end{tabular}

\section{RESULTS}

As previously mentioned, in this study a training setback was operationally defined as a lesson of training that a student had to repeat that had previously been flown. In addition, a "bottleneck" was defined as a lesson or area of training that required the student to receive additional instruction beyond what is prescribed in the syllabus to reach the mastery of that lesson or area. In other words, if a one hour lesson was required and the student took more than two hours to complete the lesson, it was considered a "bottleneck".

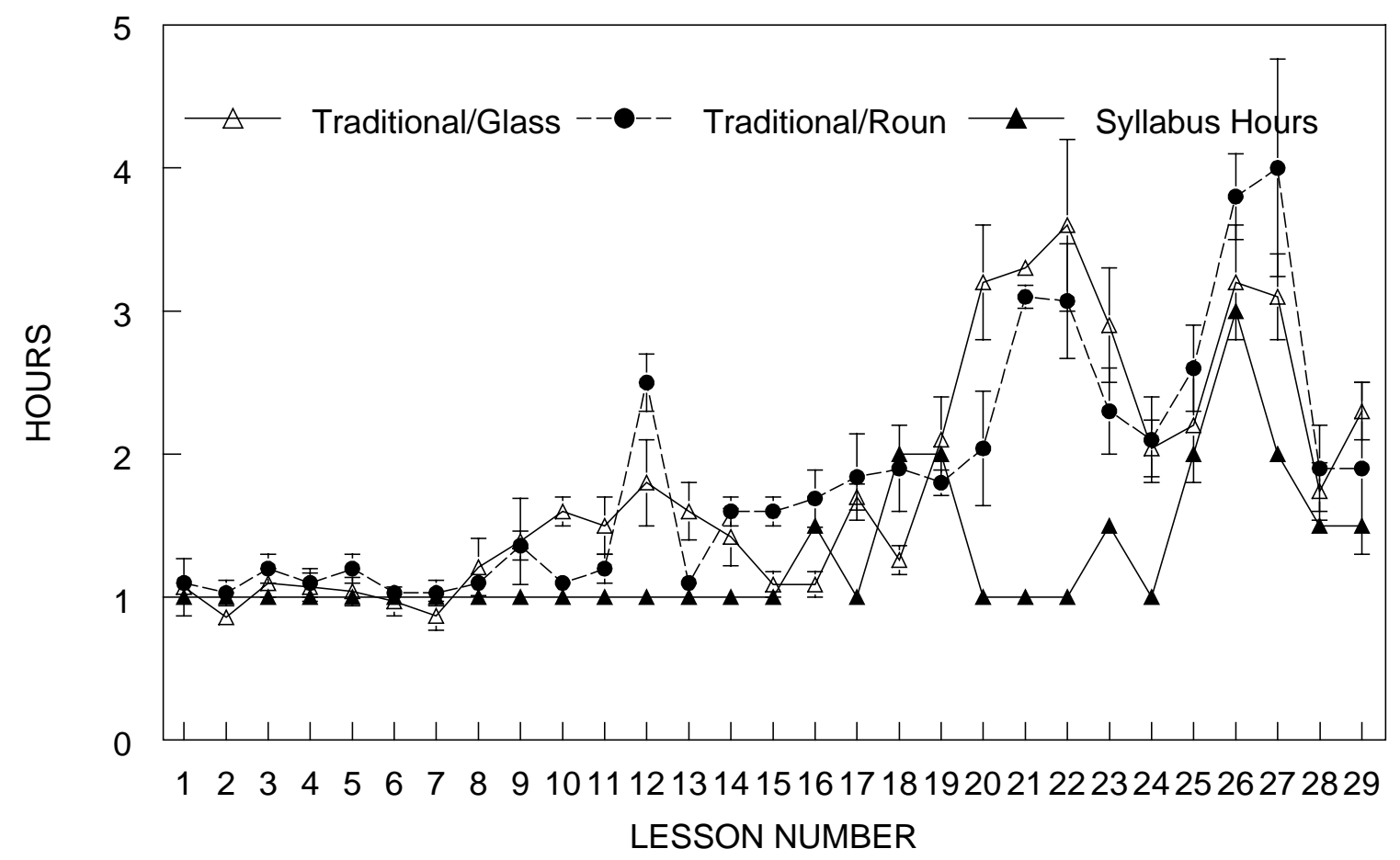

Figure 1. Illustration of the mean hours to complete each lesson in the Traditional Glass and Traditional Round Archival compared to what is prescribed in the Jeppesen training syllabus. Vertical bars equal \pm standard error of the mean. 
Figure 1 is an Illustration of the bottlenecks experienced by both the Traditional Syllabus Glass students and the Traditional Syllabus Round Archival students versus the "target time”, or recommended number of flight hours that should allow mastery of the topics and maneuvers contained in the lesson. The target time comes from the Jeppesen Instrument syllabus. As you can see from Figure 1, in both groups seven bottlenecks are evident in the syllabus: Lesson 12, Lessons 20 through 24, and Lesson 27. Lesson 12 contains the skill of VOR tracking and radial intercepting as well as partial panel tracking. Lesson 20 and 21 contain the ILS instrument approach, including the partial panel ILS. Lesson 27 is an instrument cross-country review flight. Data from these seven bottlenecks were analyzed using a 2 × 7 ANOVA (Gravetter \& Wallnau, 2004).

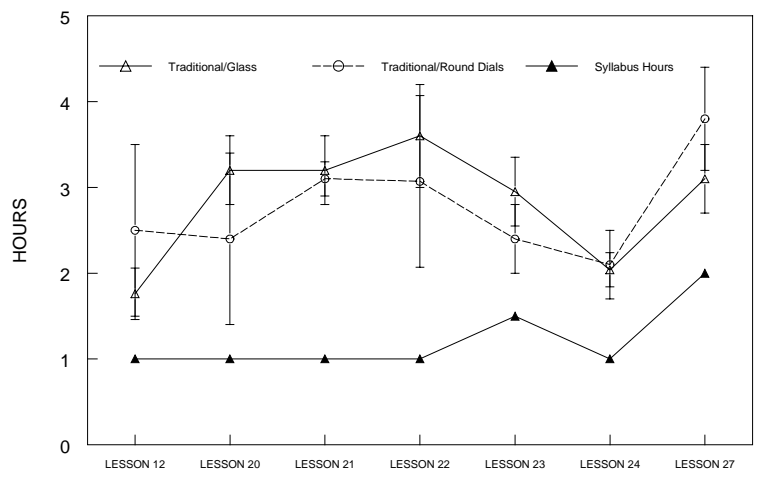

Figure 2. Illustration of the identified bottlenecks in the Traditional Glass and Traditional Round Archival compared to what is prescribed in the Jeppesen training syllabus. Vertical bars equal + standard error of the mean.

As can been seen from Figure 2, an ANOVA comparing the effects of flight training and the number of lesson flight hours between the Traditional Syllabus Round Archival group and the Traditional Syllabus Glass group revealed no significant differences, $\mathrm{F}(1,223)=$ $0.17, \mathrm{p}>0.05$.

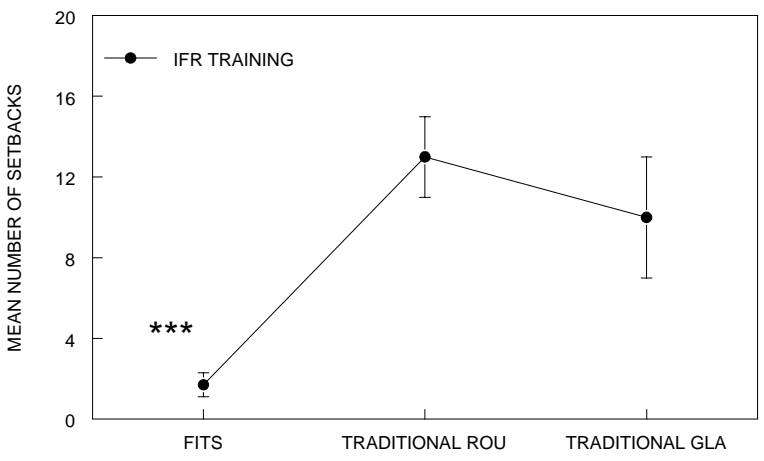

Figure 3. Illustration of the mean number of setbacks in the FITS, Traditional Glass (TRADITIONAL GLA) and Traditional Round Archival Group (TRADITIONAL ROU) compared to what is prescribed in the Jeppesen training syllabus. $* * *=$ significantly different from the traditional groups, $\mathrm{p}<0.01$. Vertical bars equal + standard error of the mean.

Figure 3 illustrates the total number of setbacks during the IFR training experienced by each of the training groups. A one way ANOVA comparing total setbacks over the Instrument training for these groups revealed a significant main effect of training, $\mathrm{F}(2,31)=8.33$, $\mathrm{p}<0.01$. Post hoc analysis using the Scheffe's test revealed that the FITS Glass group had significantly fewer setbacks over their instrument training compared to both the Traditional Syllabus Round Archival and Traditional Syllabus Glass groups.

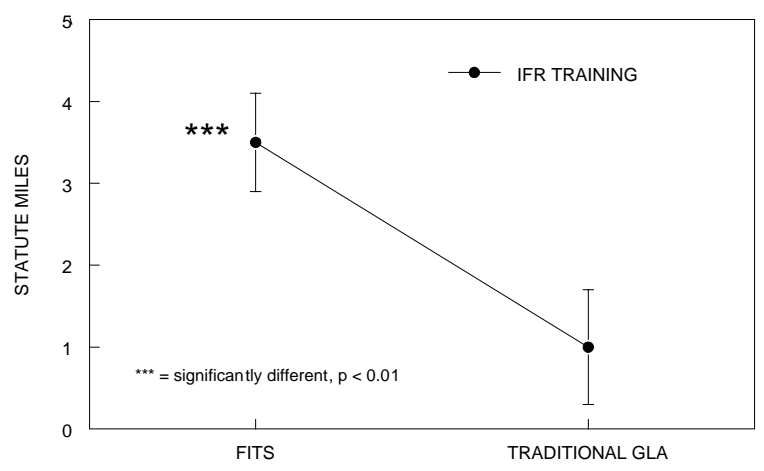

Figure 4. Illustration of the mean personal reports of visibility in the FITS group compared to the Traditional Glass trained group (TRADITIONAL GLA). Vertical bars equal \pm standard error of the mean. 


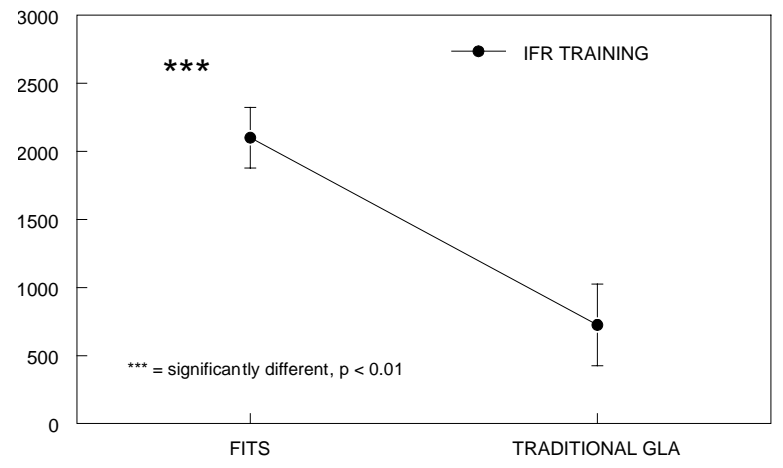

Figure 5. Illustration of the mean personal reports of ceiling in the FITS group compared to the Traditional Glass trained group (TRADITIONAL GLA). Vertical bars equal + standard error of the mean.

Figures 4 and 5 illustrate the results of several questionnaires regarding personal IFR cloud and visibility minimums. As can be seen from these Figures, the FITS Glass trained group reported as personal minimums a mean visibility of 3.6 statute miles, and a mean cloud height of 2200 feet. In contrast, a mean visibility of 1.1 statutes miles and a cloud height of 700 feet was reported in the Traditional Syllabus Glass group. These personal minimums in the FITS Glass trained group were significantly greater; selfreported personal visibility, $\mathrm{t}(28)=4.65, \mathrm{p}$ $<0.01$, and cloud minimums, t $(28)=3.89 \mathrm{p}<$ 0.01 compared to the Traditional Syllabus Glass trained pilots.

\section{DISCUSSION}

In 2003, the FAA Industry Training Standards research group recommended that a new training approach emphasizing "realistic flight scenarios" would be a more effective training approach in TAA, and perhaps even eliminate the "gap" between available safety and actual safety of the TAA (Fiduccia et al., 2003). Our data examining the effects of a FITS training approach strongly support the recommendations of the FAA. Our data suggest that it is the type of training program and not the type of aircraft that is the driving force behind the benefits of the FITS syllabus. Pilots who trained using the FITS syllabus had significantly fewer setbacks over their Instrument training compared to traditional syllabus pilots trained in a TAA. In addition, FITS trained pilots were arguably more conservative in that their personal minimums were significantly higher compared to Traditional Syllabus Glass trained pilots. This is particularly noteworthy as both groups of pilots who were trained in a TAA, regardless of the training approach, reported feeling very comfortable with the automation in the aircraft, and also with shooting an IFR approach to minimums (data not shown). Regardless of their comfort level, the increased visibility and cloud minimums reported by the FITS trained pilots suggest that although the FITS students are comfortable with the automation, they would be less likely to "launch" when visibility and clouds are low. In contrast, the significantly lower visibility and clouds minimums reported in the Traditional Syllabus Glass trained pilots (e.g. mean cloud height $=700$ feet), strongly suggests that traditional training approaches in a TAA may be inadequate.

In 2004, after the first group of students had completed the FITS combination Private and Instrument syllabus, the researchers had data that indicated that training improvements had been accomplished. Students in the FITS syllabus had fewer setbacks in their training. A setback is not simply a statistic to be compared inside a research study. A flight training setback also represents an increase in the total cost of flight training and an increase in time it takes to complete the training. A single setback can cost a student approximately $\$ 150$ extra in training costs. In 2005, when the researchers compared the number of setbacks that students encountered within the FITS syllabus, versus the traditional syllabus which had been used for years, we saw that on average, students in the FITS syllabus had ten fewer setbacks across their Private and Instrument training. That represented a savings of approximately 9 percent per student. Setbacks also have an emotional cost. Students can often get discouraged, and even drop out of flight training all together when they are faced with multiple setbacks and extra costs. The FITS syllabus, with its inherent realworld applications, fewer setbacks, less frustrations, and lower cost, was reported by students as being hard work, but it was very enjoyable to the students.

In 2005, the researchers began the second phase of the project. This time students would 
train using TAA, but using the traditional syllabus. The researchers believed at the on-set of this phase, that one of two possibilities would emerge. If improvements enjoyed by the FITS Group were also enjoyed by the Traditional Syllabus Glass Group, then the researchers could conclude that the technology of the "glass cockpit" had generated the improvements. On the other hand, if the setbacks that the Traditional Syllabus Round Dial Archival pilots suffered reappeared in the Traditional Syllabus Glass students, then the researchers could conclude that it was not the technology, but the FITS training method that created the improvements. As this paper has presented, the data collected indicates now that technology alone does not produce training benefits. The data indicates that the FITS approach, with its involvement of higher-level thinking skills, is the difference maker.

After this conclusion was drawn, the researchers wanted to determine just what type of pilot is being produced by FITS. Reducing setbacks in training and saving money are both excellent goals, but what really matters is that these pilots make better decisions than their predecessors and as a result are safer pilots. Our data suggest that this is the case. Whether conservative minimums translate into safer pilots, and whether or not these pilots remain that way over the long term, are two critical questions that will be addressed in future research at MTSU. The researchers used a series of surveys to determine the level of caution versus risk-taking that was present in the various pilot groups that were studied. The evidence indicates that when each flight lesson incorporates a decision process that involves the assessment of risk in real-world settings, that pilots will be more cautious once they are in the real-world. The FITS trained pilots were more comfortable in the IFR environment, but nevertheless more cautious than the non-FITS pilots.

\section{CONCLUSION}

Pilots that have been trained using the problem-solving, scenario-based approach that is the cornerstone of FITS, have been the beneficiary of various flight training improvements. They also have emerged from the
FITS training better prepared to deal with realworld pressures because they were trained to do so. The introduction of TAA into the civilian General Aviation flight training environment can become either a blessing or a curse. The evidence from our study indicates that TAA and FITS are a good match. TAA takes aircraft to a higher level; FITS takes flight training to a higher level. The TAA offers capabilities that could easily exceed the pilot's risk-assessment capabilities. A TAA in the hands of a pilot who has not been taught to make real-world decisions properly and who consequently becomes a risktaker is a formula for disaster. TAA and FITS are coming of age simultaneously; our research indicates that the FITS concept of flight training can reduce setbacks, save money, and minimize training time and that the transition to the TAA can best be accomplished safely with FITS. 


\section{REFERENCES}

AOPA Air Safety Foundation. (2005). Technically advanced aircraft: Safety and training. Frederick, MD: AOPA Air Safety Foundation.

Ayers, F. H. (2006). The application of scenario based recurrent training to teach single pilot resource management (SRM) under the FAA Industry Training Standards (FITS) Program. Journal of Aviation and Aerospace Research, 3, 13-25.

Billings, C. E. (1997). Aviation automation: The search for a human-centered approach. Mahwah, NJ: Lawrence Erlbaum Press.

Casner, S. M. (2005). Transfer of learning between a small technically advanced aircraft and a commercial jet transport simulator. International Journal of Applied Aviation Studies, 5(2), 307320.

Craig, P. A. (2000). Pilot in Command. McGraw Hill, New York.

Craig, P. A., Bertrand, J. E., Dornan, W., Gossett, S., \& Thorsby, K. K. (2005a). Ab Initio training in the glass cockpit era: New technology meets new pilots. Paper presented at the International Symposium on Aviation Psychology.

Craig, P. A., Bertrand, J. E., Dornan, W., Gossett, S., \& Thorsby, K. K. (2005b). Scenario-based Private/Instrument syllabus versus traditional maneuver-based syllabi: A preliminary descriptive analysis. Collegiate Aviation Review, 23, 23-27.

Dornan, W., Gossett, S., Craig, P. A., \& Beckman, W. (2006). Best evidence on FITS. Paper presented at the National Training Aircraft Symposium.

Dornan, W. A., Craig, P. A., \& Gossett, S. (2006). A modified version of the FAA Industry Training Standards (FITS) Program enhances GPS pilot proficiency and decision making skills in the general aviation pilot. Submitted manuscript.

Driskill, W. E., Weismuller, J. J., Quebe, J. C., \& Hand, D. K. (1998). Evaluation the decision-making skills of general aviation pilot (DOT/FAA/AM-98/7). Washington, DC: Federal Aviation Administration, Office of Aviation Medicine.

Fanjoy, R. O., \& Young, J. P. (2005). Flight deck automation: Line pilots insight for improved initial pilot training. International Journal of Applied Aviation Studies, 5(1), 13-23.

Federal Aviation Administration. (2004). FAA-Industry Training Standards (FITS) Program 2004. Retrieved, from the World Wide Web: http://www.faa.gov/education_research/training/fits

Fiduccia et al. (2003). General Aviation Technically Advanced Aircraft FAA-Industry Safety Study, Final Report. Retrieved April 10, 2006, from the World Wide Web: http://www.faa.gov/education_research/training/fits/research

Funk, K. H., Lyall, E. A., \& Niemczyk, M. C. (1997). Flightdeck automation problems: Perceptions and reality. In M. Mouloua \& J. M. Koonce (Eds.), Human-automation interaction: Research and practice (pp. 29-34). Mahwah, New Jersey: Lawrence Erlbaum Associates.

Glista, T. (2003, March/April). FAA/Industry Training Standards (FITS): Times (and training requirements) are a changing. FAA Aviation News, 1-4.

Gravetter, F. J., \& Wallnau, L. B. (2004). Statistics for the Behavioral Sciences (6th ed.): Thomson and Wadsworth Press.

Jensen, R. S. (1982). Pilot judgment: Training and evaluation. Human Factors, 24, 61-73.

Jeppesen. (2003). Instrument Commercial Syllabus. Englewood, CO: Jeppesen Sanderson Inc,. 
Klein, G. A. (1998). Sources of Power: How People Make Decisions. Cambridge, MA: MIT Press.

Parasuraman, R., \& Riley, V. (1997). Human and automation: Use, misuse, disuse, abuse. Human Factors, 39(2), 230-253.

Sarter, N., \& Woods, D. D. (1995). How in the world did we ever get into that mode? Human Factors, 37, 5-19.

Stokes, A. F., Kemper, K. L., \& March, R. (1992). Time-stressed flight decision making: A study of experts and novice aviators (88-TR-16). Arlington, VA: Office of Naval Research.

Young, J. P., Fanjoy, R. O., \& Suckow, M. W. (2006). Impact of glass cockpit experience on manual flight skills. Journal of Aviation and Aerospace Research, 3, 27-31. 